\title{
Coatings manufactured using magnetron sputtering technology to protect against infrared radiation for use in firefighter helmets
}

\author{
Marzena Fejdyś ${ }^{1}$, Karolina Olszewska ${ }^{1 *}$, Sylwia Kaczmarczyk ${ }^{1}$, Grzegorz Owczarek ${ }^{2}$ \\ ${ }^{1}$ Institute of Security Technologies "MORATEX", 3 M. Sklodowskiej-Curie Str., 90-505 Lodz, Poland \\ ${ }^{2}$ Central Institute for Labour Protection - National Research Institute, 48 Wierzbowa Str., 90-133 Lodz, Poland \\ "Corresponding author: e-mail: kolszewska@moratex.eu
}

\begin{abstract}
The aim of this study was to test the usefulness of magnetron sputtering technology to produce coatings on selected elements of a firefighter's helmet to protect against infrared radiation (PN-EN 171 standard). The scope of research includes testing the deposition produced via magnetron sputtering of metallic and ceramic coatings on plastics, which are used to manufacture the components comprising the personal protection equipment used by firefighters. The UV-VIS, NIR used to research the permeation coefficients and reflections for light and infrared light and the emission spectrometry with ICP-AES used for the quantitative analysis of elements in metallic and ceramic coatings. Microstructural and micro-analytical testing of the coatings were performed using scanning electron microscopy (SEM). Measurements of the chemical compositions were conducted using energy-dispersive X-ray spectroscopy (EDS). The hardnesss of the coatings were tested using a indentation method, and the coating thicknesses were tested using a ellipsometry method.
\end{abstract}

Keywords: personal protection equipment, firefighter helmet, protective coatings, infrared radiation magnetron sputtering technology.

\section{INTRODUCTION}

The basic feature of protective coatings used in personal protection equipment is to improve their protective and functional properties. There are three types of protective coatings applied to structural elements comprising personal protection equipment made from plastic or glass: paint, metallic, and metallic-dielectric (interference).

Metallic coatings are applied mainly on so-called see-through elements (e.g., visors). Thin metallic or metallic-dielectric coatings allow optical spectral modification for the transmittance and reflection characteristics in visors. The following parameters should be used to characterise the transmittance-reflective properties of these coatings: light transmittance and spectral infrared transmittance coefficients. The following coefficients are used to characterise the aforementioned parameters ${ }^{\mathbf{1}, \mathbf{2}}$ :

- light transmittance coefficient (light transmittance $\left.\left(\tau_{v}\right)\right)$,

- average spectral infrared transmittance coefficient over a wavelength range from 780 to $1400 \mathrm{~nm}\left(\tau_{A}\right)$;

- average spectral infrared transmittance coefficient over a wavelength range from 780 to $2000 \mathrm{~nm}\left(\tau_{N}\right)$;

- average spectral infrared reflection coefficient over a wavelength range from 780 to $2000 \mathrm{~nm}\left(R_{N}\right)$.

The main research thrust in the production of protective coatings used in structural elements of personal protection equipment is physical deposition methods from the gas phase, i.e., PVD (Physical Vapour Deposition) ${ }^{3}$. The coating deposition process using the PVD method is conducted in a reduced pressure environment, frequently utilizes ions and is characterized by a number of different physical adhesion phenomena including: vapour deposition, sputtering, atomization, and implanting of ions or metallic and non-metallic elements. The common feature of these methods is the crystallization of metal vapours or phases from plasma (PAPVD - Plasma Assisted PVD). Contrary to conventional procedures for applying metallic coatings to materials, PVD allows the production of thin layers of a predetermined structure on a surface. The coatings may be deposited on a cold substrate or one that is heated to between $200^{\circ} \mathrm{C}-500^{\circ} \mathrm{C}^{4}$. The temperature required for deposition of a protective layer depends mainly on the type of the substrate. However, it must be strongly stressed that any changes to the PVD processing parameters have a significant impact on the structure of the coating. The composition and properties of the coatings deposited using the PVD method depend on ${ }^{5}$ :

- the speed of sputtering;

- the distance between the deposited material - target and the substrate;

- the temperature of the substrate;

- the pressure of the reactive gas;

- the density of the evaporated or sputtered atoms;

- the degree of ionization of the reactive gas.

These parameters, together with the substrate properties (chemical composition, microstructure, topography, etc.), determine the mechanical properties of the coatings. The deposition of the coating using the PVD process is not accompanied by chemical transformations and the only changes are in the state of aggregation on the introduced substance. The literature contains many reports on the production of coatings applied on various materials using the PVD method. One example includes thin layers of transition metal nitrides ${ }^{6}$, which are commonly used as protective layers due to their high hardness, chemical inertness and excellent abrasive resistance. Titanium nitride (TiN) is noteworthy in this group. When titanium nitride is applied on a material, it increases the wear and tear resistance, durability and corrosion resistance. In addition it has exhibited the ability to reflect infrared radiation, which contributes to the creation of "heat mirrors". However, its main disadvantage is its low oxidization resistance in the temperature range from approx. $450^{\circ} \mathrm{C}-550^{\circ} \mathrm{C}$. This phenomenon can be prevented by modifying this layer to include small amounts of $\mathrm{Al}, \mathrm{Cr}$ or $\mathrm{Si}$, which increase the oxidization resistance ${ }^{7,8}$. Other 
compounds from the nitride group used for the creation of layers possessing interesting properties may include zirconium nitride $(\mathrm{ZrN})^{\mathbf{9}}$ and chromium nitride $(\mathrm{CrN})^{\mathbf{1 0}}$. These layers also exhibit a high resistance to abrasion and corrosion. In addition, $\mathrm{ZrN}$ performs an aesthetic function by giving the coated layers a golden colour ${ }^{11,12}$. However, aluminium modified $\mathrm{CrN}$ layers can be used for higher temperatures ${ }^{\mathbf{1 3}}$, have a higher hardness and a lower friction coefficient ${ }^{14,15}$. Depending on the quantity of the administered $\mathrm{Al}$ in the $\mathrm{CrAIN}$ layers, these materials have demonstrated stability at temperatures of up to $900^{\circ} \mathrm{C}^{\mathbf{1 6}}$. At the same time, increases in the $\mathrm{Al}$ content in $\mathrm{CrAlN}$ layers gradually reduce the thermal resistance, despite improving the adhesion of the layer to the substrate ${ }^{\mathbf{1 7}}$. However, there are a growing number of applications in which the properties provided from a single coating layer are insufficient. The latest research has focused on the development of multilayer coatings with markedly better physical and mechanical properties ${ }^{18-22}$. One example is multi-layer coatings using a vacuum sputtered solid solution of indium oxide (III) and tin oxide (IV) (ITO) and modification via reinforcement with carbon nanotubes $(\mathrm{CNT})^{23}$, aluminium ${ }^{24}$ or silver ${ }^{25}$. Another solution concerns the application of antimony supplemented with tin oxide (ATO), or the application of single-layer tin oxide ${ }^{26}$ and titanium oxide due to the unique UV radiation absorption properties of a $\mathrm{SiO}_{2}$ layer, which would act as an excellent thermal barrier ${ }^{27}$. Multi-layer coating examples can include the use of dielectric layers such as $\mathrm{TiO}_{2}$ or multi-layer $\mathrm{TiO}_{2} / \mathrm{SiO}_{2}$ layers deposited on the surface of a material. These layers exhibit a high reflectivity in the infrared range ${ }^{\mathbf{2 8 , 2 9}}$. The literature also contains information on ${ }^{\mathbf{3 0}, 31}$ the production of coating layers from metallic elements using PVD (physical vapour deposition) including: chrome, phosphor-bronze, silver, copper and multi-layers of $\mathrm{SiO}_{2} / \mathrm{Cu}$, or $\mathrm{SiO}_{2} / \mathrm{Ag}$ on a polycarbonate substrate to protect the eyes and face. The article $^{32}$ presents the characteristics of interference filters designed to protect against harmful infrared radiation using copper $(\mathrm{Cu})$ and aluminium $(\mathrm{Al})$. These filters were fabricated using vacuum deposition techniques.

Over the years, significant progress has been made in the development of materials used for personal protection equipment to modify their chemical and physical properties. The latest types of personal protection, despite benefitting from significant technical progress, still do not fully protect against thermal threats for all tactical and operational activities. The majority of applied personal protection systems are insulating in nature and do not protect the user fully against infrared radiation.

One thesis describes the use of magnetron sputtering technology for deposition of elements including: Ti, $\mathrm{Cr}, \mathrm{Ni}, \mathrm{Al}, \mathrm{N}$, and $\mathrm{Si}$ on components of a firefighter's helmet to create coatings to protect against heat from infrared radiation in accordance with the PN-EN 171:2005 standard.

As part of this research, magnetron sputtering technology was used to develop coatings to protect against infrared radiation in personal protection equipment.

Correlation of the information collected over the course of the tests combined with the known conditions during the coating process allowed the development of technical guidelines for the production of protective coatings with transmittance-reflective properties using the magnetron sputtering method.

\section{EXPERIMENTAL SETUP}

\section{Material}

The substrates for the protective coatings used in these tests were $100 \mathrm{~mm}$ x $100 \mathrm{~mm}$ samples cut from the structural elements of firefighter helmets including the helmet shell, eye and face protection (visor) plastic material. Structural elements of the helmet were provided by Kaliskie Zakłady Przemysłu Terenowego w Kaliszu Sp. z o.o. (KZPT/Poland). Polyamide 66 with $25 \%$ glass fibre content (Ultramid ${ }^{\circledR} \mathrm{A} 3 \mathrm{XZG}$, BASF The Chemical Company/Germany) was used to make the helmet shell and a polycarbonate viewfinder was used (LEXAN ${ }^{\circledR} 141 \mathrm{R}$, GE Plastics/U.S.). The materials selected for use as protective coatings included $\mathrm{Ti}, \mathrm{Ni}$, and $\mathrm{Cr}$, which were administered onto the transparent polycarbonate substrates. Ceramic coatings of AlTiN, $\mathrm{Ti} / \mathrm{N}$, and $\mathrm{TiN} / \mathrm{SiN}$ were designed to cover the shell of a firefighter's helmet, additionally $\mathrm{Al}$ and $\mathrm{Si}$ were used.

\section{Protective coating deposition method}

The metallic and ceramic coatings were deposited using magnetron sputtering with two devices: a B-90 and an SMK2K at the Institute of Materials Engineering, Technical University of Lodz, Poland. Prior to disposition, each substrate was washed in water at $30^{\circ} \mathrm{C}$ using a detergent (Chem-R Glass, CHEMPUR//Poland) and then in isopropylene alcohol (BRENNTAG GmbH/Germany) in an ultrasound washer (Sonic 6/Polsonic/Poland) for $30 \mathrm{~min}$. at a frequency of $40 \mathrm{kHz}$. Afterwards, the samples were dried at $30^{\circ} \mathrm{C} \pm 1^{\circ} \mathrm{C}$ for $30 \mathrm{~min}$. $\pm 1 \mathrm{~min}$. and mounted using chromium-nickel wire in the vacuum chamber of either the B-90 or SMK2K machines. During the deposition of the PA/TiN/SiN and PA/AlTiN coatings on PA substrate, a mixture of $30 \% \mathrm{Ar}$ and $70 \% \mathrm{~N}_{2}$ was used. Additional nitrogen was used ( $25 \mathrm{sccm}$ ) for coating the PA/TiN/SiN, which was deposited via sputtering of a target composed of a mixture of silicon and titanium. The PA/AlTiN coating PA substrate was deposited from a target made from titanium and aluminium tiles laid in an alternating pattern. The deposition of the PC/ TiN coating PC substrate was preceded by 8 mins. of sputtering of pure titanium in the presence of nitrogen. Afterwards, nitrogen was added to the vacuum chamber to obtain the target coating. The deposition parameters for the metallic and ceramic coatings selected for the structural elements of the firefighter helmets are summarized in Table 1. The list of non-modified and surface modified samples used in the magnetron sputtering process is presented in Table 2 .

\section{Testing of the hardness of the coatings}

The analysis of micro-hardness $(\mathrm{H})$ and the reduced modulus $\left(\mathrm{E}^{*}\right)$ of the samples was performed with the use of NanoTest 600 apparatus (MicroMaterials Ltd., UK), equipped with a diamond penetrator (Indenter) of Berkovich geometry. Everytime 10 indentations was executed on each sample. The measurements were performed under controlled conditions of temperature $\mathrm{T}=23 \pm 1^{\circ} \mathrm{C}$ and 
Table 1. Process parameters used for the deposition of the metallic and ceramic coatings on samples originating from the structural elements of firefighter helmets

\begin{tabular}{|c|c|c|c|c|c|c|c|c|c|}
\hline $\begin{array}{l}\text { Parameter } \\
\text { Sample }\end{array}$ & $\begin{array}{l}\text { Method of } \\
\text { deposition }\end{array}$ & $\begin{array}{c}\text { Initial } \\
\text { pressure } \\
{[\mathrm{Pa}]}\end{array}$ & $\begin{array}{c}\text { Temperature } \\
{\left[{ }^{\circ} \mathrm{C}\right]}\end{array}$ & $\begin{array}{l}\text { Working } \\
\text { pressure } \\
{[\mathrm{Pa}]}\end{array}$ & $\begin{array}{c}\text { Gas } \\
\text { flow } \\
{[\mathrm{sccm}]}\end{array}$ & $\begin{array}{l}\text { Power in } \\
\text { magnetron } \\
{[\mathrm{kW}]}\end{array}$ & $\begin{array}{c}\text { Deposition } \\
\text { time } \\
\text { [s] }\end{array}$ & Polarization & $\begin{array}{l}\text { Rotation } \\
\text { samples }\end{array}$ \\
\hline $\mathrm{PC} / \mathrm{Ti}$ & $\begin{array}{c}\text { The } \\
\text { continuous } \\
\text { SMK2K }\end{array}$ & $2.510^{-3}$ & 50 & 0.4 & $\begin{array}{l}\text { (Ar) } \\
15.5\end{array}$ & 0.5 & 720 & 0 & NO \\
\hline $\mathrm{PC} / \mathrm{Cr}$ & $\begin{array}{c}\text { The } \\
\text { continuous } \\
\text { SMK2K }\end{array}$ & $2.510^{-3}$ & 50 & 0.4 & $\begin{array}{l}\text { (Ar) } \\
13.5\end{array}$ & 0.5 & 240 & 0 & NO \\
\hline $\mathrm{PC} / \mathrm{Ni}$ & $\begin{array}{c}\text { The } \\
\text { continuous } \\
\text { B-90 }\end{array}$ & $2.510^{-3}$ & 50 & 0.4 & $\begin{array}{l}\text { (Ar) } \\
20.0\end{array}$ & 0.5 & 300 & 0 & YES \\
\hline PA/AITiN & $\begin{array}{l}\text { The impulse } \\
\text { SMK2K }^{1}\end{array}$ & $2.510^{-3}$ & 50 & $\begin{array}{c}0.77 \\
\text { (molar ratio } \\
\text { Ar/ } \mathrm{N}_{2} ; \\
30 \% / 70 \% \text { ) }\end{array}$ & $\begin{array}{l}\text { (Ar) } \\
10.0\end{array}$ & $\begin{array}{c}7.1 \\
\text { (mass ratio } \\
\text { Al: Ti; } 1: 16 \text { ) }\end{array}$ & 14400 & 0 & NO \\
\hline PA/TiN & $\begin{array}{c}\text { The } \\
\text { continuous } \\
\text { B-90 }\end{array}$ & $2.210^{-3}$ & 50 & 0.4 & $\begin{array}{l}\left(\mathrm{N}_{2}\right) \\
7.25 \\
(\mathrm{Ar}) \\
22.0\end{array}$ & 3.0 & 7248 & 0 & YES \\
\hline $\mathrm{PA} / \mathrm{TiN} / \mathrm{SiN}$ & $\begin{array}{l}\text { The impulse } \\
\text { SMK2K }^{\mathrm{a}}\end{array}$ & $2.510^{-3}$ & 50 & $\begin{array}{c}0.77 \\
\text { (molar ratio } \\
\text { Ar/ } \mathrm{N}_{2} ; \\
30 \% / 70 \% \text { ) }\end{array}$ & $\begin{array}{l}\left(\mathrm{N}_{2}\right) \\
25.0\end{array}$ & $\begin{array}{c}7.1 \\
\text { (mass ratio } \\
\text { Si: Ti; } 1: 16 \text { ) }\end{array}$ & 14400 & -50 & YES \\
\hline
\end{tabular}

${ }^{a}$ gas pulse frequency $(1.1 \mathrm{~Hz})$.

Table 2. Non-modified and surface modified samples used for the magnetron sputtering process

\begin{tabular}{|c|c|c|c|}
\hline No. & $\begin{array}{l}\text { Marking of } \\
\text { the } \\
\text { samples }\end{array}$ & $\begin{array}{l}\text { Characteristics of the } \\
\text { samples }\end{array}$ & Comments \\
\hline 1 & $\mathrm{PC}$ & Polycarbonate & \multirow{4}{*}{$\begin{array}{l}\text { Transparent } \\
\text { samples }\end{array}$} \\
\hline 2 & $\mathrm{PC} / \mathrm{Ti}$ & $\begin{array}{l}\text { Polycarbonate with } \mathrm{Ti} \\
\text { coating }\end{array}$ & \\
\hline 3 & $\mathrm{PC} / \mathrm{Cr}$ & $\begin{array}{c}\text { Polycarbonate with } \mathrm{Cr} \\
\text { coating }\end{array}$ & \\
\hline 4 & $\mathrm{PC} / \mathrm{Ni}$ & $\begin{array}{l}\text { Polycarbonate with } \mathrm{Ni} \\
\text { coating }\end{array}$ & \\
\hline 5 & PA & Polyamide & \multirow{4}{*}{$\begin{array}{l}\text { Non- } \\
\text { transparent } \\
\text { samples }\end{array}$} \\
\hline 6 & PA/AITiN & $\begin{array}{c}\text { Polyamide with AITiN } \\
\text { coating }\end{array}$ & \\
\hline 7 & $\mathrm{PA} / \mathrm{TiN}$ & $\begin{array}{l}\text { Polyamide with TiN } \\
\text { coating }\end{array}$ & \\
\hline 8 & $\begin{array}{c}\mathrm{PA} / \mathrm{TiN} / \mathrm{Si} \\
\mathrm{N}\end{array}$ & $\begin{array}{l}\text { Polyamide with } \\
\text { TiN/SiN coating }\end{array}$ & \\
\hline
\end{tabular}

the relative humidity of $60 \pm 5 \%$. During the analyses, the load force of the penetrator was controlled („Load controlled" module), experimentally determined to Pmax $=5 \mathrm{mN}$. The indenter was loaded up to the presumed force Pmax at the rate of $\mathrm{dP} / \mathrm{dt}=0.5 \mathrm{mN} / \mathrm{s}$, then it was left for $10 \mathrm{~s}$ at the point of applying the maximum force ad consequently relieved at the same rate. This allowed for recording the course of curves of the penetration depth in relation to force (ie. load-relief curves), on the basis of which the micro-mechanical parameters of samples' top layers were determined.

\section{Transmittance-reflection property tests}

A correlation of the obtained values of the light transmittance coefficient $\left(\boldsymbol{\tau}_{v}\right)$ with the values of the low spectral infrared transmittance coefficients $\left(\tau_{A}\right.$ and $\left.\tau_{N}\right)$ are a very important element of the assessment for the viewfinders used in firefighter helmets. The determination of a filter protecting against infrared radiation may be determined from the value of the light transmittance coefficient. The maximum values for the spectral infrared transmittance coefficients are then determined according to the PN-EN 171:2005 standard.
There are presently no standardized assessment criteria for non-transparent materials used to produce firefighter helmets. Therefore, for some materials, a reference was made to the infrared radiation reflection coefficient over the wavelength range from 780 to $2000 \mathrm{~nm}$. The assessment of the selected elements of the firefighter helmets containing the applied protective coatings was conducted via a comparison of the average infrared transmittance coefficient for the samples with and without the coatings. It was assumed that the optical properties of the ceramic coating applied on the non-transparent materials exposed to infrared radiation should be at a level no lower than that for the transparent elements. This means that the average infrared radiation reflection coefficient over the wavelength range from 780 to $2000 \mathrm{~nm}$ should not be smaller than $60 \%$.

A pair of two-beam spectrophotometers was used in the tests:

- CARY 5E (Agilent Technologies/U.S.) - for the measurement of spectral transmittance characteristics;

- CARY 5000 (Agilent Technologies/U.S.) - for the measurement of reflection spectral characteristics.

Both spectrophotometers measure the spectral characteristics of the transmittance, absorption and reflection over the range from 180 to $3000 \mathrm{~nm}$ with a minimum measurement stroke of $1 \mathrm{~nm}$. The uncertainty of the transmittance/reflection measurement was determined to be $0.0001 \%$.

\section{Testing of the surface structure of the coatings using the SEM-EDS method}

Testing of the surface structure of the coatings was conducted using a scanning electron microscope in field emission mode (S-4700, Hitachi/Japan) equipped with an energy dispersion spectrometer (EDS). The resolution of the microscope in the SE mode was $1.5 \mathrm{~nm}$ (at $15 \mathrm{kV}$ ) with a working distance of $12 \mathrm{~mm}$. The spectra were recorded at an induction voltage $15 \mathrm{kV}$. The spectra of the characteristic X-ray radiation obtained using the EDS 
detection system provided information on the elements present in the sample by comparing the intensity of the peaks corresponding to individual elements. This permitted a semi-quantitative determination of the coating contents. These studies were conducted at the Institute of General and Organic Chemistry of the Technical University of Lodz.

\section{Determination of the elemental coating contents using inductively coupled plasma atomic emission spectroscopy (ICP-AES)}

The individual contents of the elements in the samples containing applied coatings were determined using inductively coupled plasma atomic emission spectroscopy (ICP-AES) in a spectrometer (IRIS/AP, Thermo Jarrell Ash/U.S.). The calibration of the spectrometer was conducted with the use of the ICP - MS category template ("ICP multi - element standard solution VI for ICP-MS"| Merck/Germany). Prior to analysis, the samples were digested in an MLS 1200 (MILESTONE/Italy) using microwaves and appropriately concentrated, spectrally pure acids $\left(\mathrm{HNO}_{3}\right.$ and $\left.\mathrm{H}_{2} \mathrm{SO}_{4}\right)$. The results obtained from the analysis were verified using control samples. These studies were conducted at the Institute of General and Organic Chemistry at the Technical University of Lodz.

\section{Thickness testing}

The thickness measurement of the coatings was performed using variable angle spectroscope ellipsometry via a spectroscope (V-VASE instrument, J.A. Woollam Co./U.S.) over a spectral range from 300-1000 nm with analysing beam falling angles of $65^{\circ}$ and $75^{\circ}$. The coating thickness tests using the ellipsometry method were based on measurements of the changes in the state of the polarization of monochromatic light reflected or transmitted through the sample. Any light polarization was determined using the relation between the amplitudes and phases for two waves of linear polarization whose electric field vectors are within falling plane of the analysing beam on the sample $(p)$ and in the perpendicular plane $(s)$. The determination of the thickness and/or sample refraction coefficient via ellipsometry measurements was performed by modelling the measured layers over the course of a four-stage procedure:

- ellipsometry measurement;

- construction of a layered model corresponding to the structure of the measured optical layout;

- adaptation of the experimental data to the assumed layered model;

- calculation of the thickness and/or optical constants obtained from the best adaptation criterion.

The thickness tests were conducted at the Centre of Molecular and Macromolecular Studies in Lodz, which is part of the network of the Polish Academy of Sciences.

\section{RESULTS AND DISCUSSION}

\section{Hardness testing of the coating layers}

The micro-mechanical tests allowed the determination of the hardness of the metallic and ceramic coatings and changes in the hardness values in relation to different substrates: polycarbonate and polyamide. Table 3 lists the hardness values of the metallic and ceramic coatings applied on the samples taken from the structural elements of the firefighter helmets.

For the metallic coatings, the obtained hardnesses were in the range from $223 \pm 4 \mathrm{MPa}$ to $241 \pm 5 \mathrm{MPa}$,

Table 3. Nano-hardness of the metallic and ceramic coatings applied to the samples taken from structural elements of firefighter helmets

\begin{tabular}{|l|c|c|c|}
\hline No. & Sample & $\begin{array}{c}\text { Hardness } \\
{[\mathrm{MPa}]}\end{array}$ & Reduced module [GPa] \\
\hline 1 & $\mathrm{PC}$ & $223 \pm 4$ & $3.6 \pm 0.0$ \\
\hline 2 & $\mathrm{PC} / \mathrm{Ti}$ & $241 \pm 5$ & $3.8 \pm 0.1$ \\
\hline 3 & $\mathrm{PC} / \mathrm{Ni}$ & $225 \pm 7$ & $3.5 \pm 0.1$ \\
\hline 4 & $\mathrm{PC} / \mathrm{Cr}$ & $205 \pm 10$ & $3.1 \pm 0.1$ \\
\hline 5 & $\mathrm{PA}$ & $186 \pm 6$ & $2.9 \pm 0.2$ \\
\hline 6 & $\mathrm{PA} / \mathrm{A} / \mathrm{TiN}$ & $3446 \pm 124$ & $49.6 \pm 0.1$ \\
\hline 7 & $\mathrm{PA} / \mathrm{TiN}$ & $2267 \pm 201$ & $23.2 \pm 0.2$ \\
\hline 8 & $\mathrm{PA} / \mathrm{TiN} / \mathrm{SiN}$ & $846 \pm 56$ & $7.6 \pm 0.3$ \\
\hline
\end{tabular}

whereas for ceramic coatings, the obtained hardnesses were in the range from $3446 \pm 124 \mathrm{MPa}$ to $2267 \pm 201$ GPa. The highest hardness was recorded for the PA/ AlTiN case. The input of aluminium to the classical material used for coatings, i.e., titanium nitride (TiN), leads to fragmentation of the coating structure. The input of aluminium in the TiAlN for industrial PVD processes resulted in interference of the growth of TiN crystals. The increasing aluminium content is accompanied by decreasing crystallite size, which results in increasing hardness of these coatings. The presence of aluminium substantially improves the TiN resistance to oxidization as a result of the $\mathrm{Al}_{2} \mathrm{O}_{3}$ coating created on the substrate and the emission of $\mathrm{Al}_{2} \mathrm{TiO}_{5}$, which reduces the diffusion of oxygen ${ }^{33,34}$. An analysis of the results demonstrated differentiation in the reduced module for the tested ceramic coatings $(\mathrm{E}=7.6 \pm 0.3 \mathrm{GPa} \div 49.6$ $\pm 0.1 \mathrm{GPa})$. As for the metallic coatings, the reduced modulus is at the same level of values $(\mathrm{E}=3.5 \pm 0.1$ $\mathrm{GPa} \div 3.8 \pm 0.1 \mathrm{GPa})$.

\section{Testing of the transmittance-reflection properties}

The following values were calculated for the samples with applied metallic coatings:

- light transmittance coefficient (light transmittance);

- average spectral infrared transmittance coefficient over a wavelength range from 780 to $1400 \mathrm{~nm}$;

- average spectral infrared transmittance coefficient over a wavelength range from 780 to $2000 \mathrm{~nm}$;

- average spectral infrared reflection coefficient over a wavelength range from 780 to $2000 \mathrm{~nm}$.

For samples with applied ceramic coatings, the following values were calculated:

- average spectral infrared transmittance coefficient over a wavelength range from 780 to $2000 \mathrm{~nm}$;

- average spectral infrared reflection coefficient over a wavelength range from 780 to $2000 \mathrm{~nm}$.

The results of these tests are described in Table 4.

Comparing the calculated transmittance coefficients from the tested samples (Table 4) with the requirements defined in the PN-EN 171:2005 standard, it is clear that none of the samples containing applied metallic coatings (samples 1 to 3 ) meet the requirements. For the PC/Ti and $\mathrm{PC} / \mathrm{Ni}$ samples, the light transmittance coefficients are $12.57 \%$ and $14.30 \%$, respectively, which correspond 
Table 4. Transmittance and reflection coefficients of the tested samples containing applied metallic and ceramic coatings

\begin{tabular}{|c|c|c|c|c|c|}
\hline \multirow[b]{2}{*}{ No. } & \multirow[b]{2}{*}{ Sample } & \multirow[b]{2}{*}{$\begin{array}{l}\text { Light transmittance } \\
\text { coefficient } T_{v}[\%]\end{array}$} & \multicolumn{2}{|c|}{ Average spectral infrared transmittance coefficient } & \multirow[b]{2}{*}{$\begin{array}{c}\text { Infrared reflection coefficient R } \\
\text { from } 780 \text { to } 2000 \mathrm{~nm} \\
{[\%]}\end{array}$} \\
\hline & & & $\begin{array}{c}T_{A} \\
\text { from } 780 \text { to } 1400 \mathrm{~nm} \\
{[\%]}\end{array}$ & $\begin{array}{c}\boldsymbol{T}_{N} \\
\text { from } 780 \text { to } 2000 \mathrm{~nm} \\
{[\%]}\end{array}$ & \\
\hline 1 & $\mathrm{PC} / \mathrm{Ti}$ & 12.57 & 12.42 & 11.51 & 54.48 \\
\hline 2 & $\mathrm{PC} / \mathrm{Cr}$ & 4.37 & 7.85 & 7.67 & 64.83 \\
\hline 3 & $\mathrm{PC} / \mathrm{Ni}$ & 14.30 & 12.10 & 10.21 & 61.66 \\
\hline 4 & PA/AITiN & 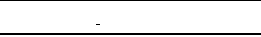 & - & - & 17.40 \\
\hline 5 & PA/TiN & - & - & - & 46.32 \\
\hline 6 & PA/TiN/SiN & - & - & - & 34.99 \\
\hline
\end{tabular}

to prepared filters at levels of: 4-3, 4-2.5, 4-2, 4-1.7, 4-1.4, and 4 -1.2. For the $\mathrm{PC} / \mathrm{Cr}$ sample, the light transmittance coefficient is $4.37 \%$, and corresponds to a filter level of 4-4. The average spectral infrared transmittance coefficients over the range from 780-2000 nm for applied metallic coating samples $(\mathrm{PC} / \mathrm{Cr}$ and $\mathrm{PC} / \mathrm{Ni}$ ) have values conforming to the requirements in the PN-EN 171:2005 standard. For all the samples, values larger than the maximum value of average spectral infrared transmittance coefficient over the range from $780 \mathrm{~nm}-1400 \mathrm{~nm}$ were observed. A positive result was recorded for the $\mathrm{PC} / \mathrm{Cr}$ and $\mathrm{PC} / \mathrm{Ni}$ transparent samples evaluated for compliance with the criterion set for increased infrared reflection. The testing of the reflection coefficient for non-transparent samples containing ceramic coatings indicated which of the tested coatings reflected the most infrared radiation (on average over the entire range from 780 to $2000 \mathrm{~nm}$ ). The results presented in Table 4 clearly indicate that the PA/TiN sample exhibits the highest value of infrared reflection.

The surface layer for this sample constitutes the best potential protection against infrared radiation, considering the series of samples containing the ceramic coatings.

Testing the surface structure of the coatings using the SEM-EDS method

Images were taken of the polycarbonate substrate (template) (LEXAN $\left.{ }^{\circledR} 141 \mathrm{R}\right)$ and metal layers deposited (titanium, chrome and nickel), using scanning electron microscopy to determine the morphology of the created surfaces. EDS was used to determine the types of elements found on the surface of the tested samples containing metallic coatings. Figure 1 shows an example of the surface of the metallic $\mathrm{Cr}$ coating on a polycarbonate substrate (LEXAN $\left.{ }^{\circledR} 141 \mathrm{R}\right)(\mathrm{PC} / \mathrm{Cr})$ and its binary image.

The results of SEM-EDS tests conducted on the metallic coatings for both the surface distribution of characteristic X-ray radiation and the linear distribution showed the presence of zones containing increased concentrations of $\mathrm{Ti}, \mathrm{Ni}$ and $\mathrm{Cr}$. SEM observations of the metallic coatings exhibited even distributions of particles and the fill space between the particles, confirming the proper coating deposition conditions. The tested layers do not appear to possess any visible cracks or holes. Based on the SEM images, there is no evidence that non-organic particles became embedded in the polymer matrix. Based on the scale in the images, the tested area possesses a coating containing micro- and nanometre sized particles. This means that the metals present on the surface of the polycarbonate substrates are found in the form of single particles, as was confirmed thickness tests using the varying-angle spectroscope ellipsometry method, which showed thicknesses in the range from $13.5 \mathrm{~nm} \pm 0.2 \mathrm{~nm}$ to $20.3 \mathrm{~nm} \pm 0.5 \mathrm{~nm}$ (Table 5).

The tests on the polycarbonate substrate (LEXAN $\left.{ }^{\circledR} 141 \mathrm{R}\right)$ (template) determined the presence of peaks related to

Table 5. Thicknesses of the metallic coatings on the polycarbonate substrate

\begin{tabular}{|l|c|c|}
\hline No. & Sample & $\begin{array}{c}\text { Thickness } \\
{[\mathrm{nm}]}\end{array}$ \\
\hline 1 & $\mathrm{PC} / \mathrm{Ti}$ & $13.5 \pm 0.5$ \\
\hline 2 & $\mathrm{PC} / \mathrm{Cr}$ & $20.3 \pm 0.5$ \\
\hline 3 & $\mathrm{PC} / \mathrm{Ni}$ & $17.2 \pm 0.2$ \\
\hline 4 & $\mathrm{PA} / \mathrm{AlTiN}$ & $143.5 \pm 0.5$ \\
\hline 5 & $\mathrm{PA} / \mathrm{TiN}$ & $147.3 \pm 0.3$ \\
\hline 6 & $\mathrm{PA} / \mathrm{TiN} / \mathrm{SiN}$ & $151.2 \pm 0.2$ \\
\hline
\end{tabular}

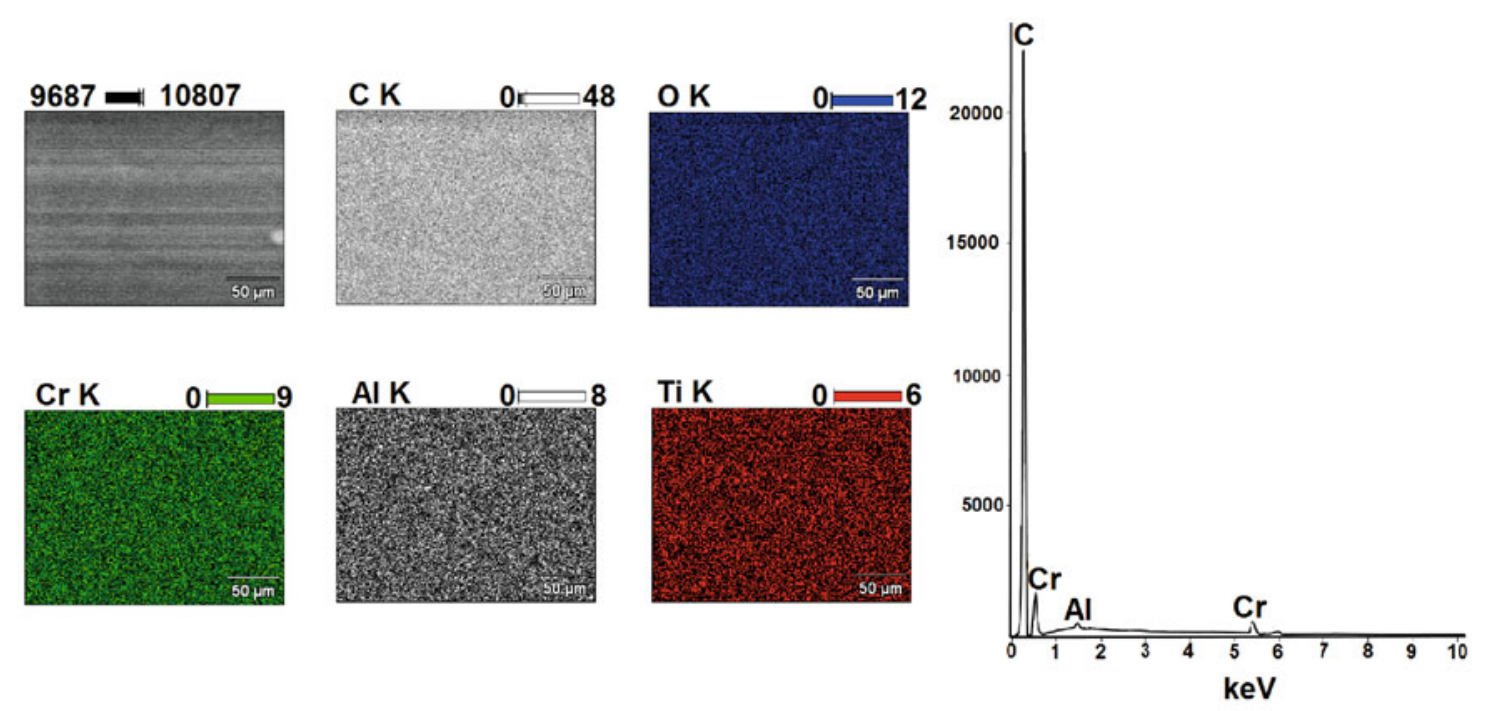

Figure 1. Results of the SEM-EDS testing (surface and linear distribution) on $\mathrm{PC} / \mathrm{Cr}$ 
the presence of $\mathrm{C}$ and $\mathrm{O}$, which result from coating particles in the structure of the polycarbonate polymers. Additionally, the presence of other particles was confirmed, including: $\mathrm{Na}, \mathrm{Br}$ and $\mathrm{Al}$, which are most likely related to leftover catalyzers used in the production of polycarbonates or originating from external environmental causes.

SEM-EDS analysis included a polyamide Ultramid ${ }^{\circledR}$ A3XZG5 substrate sample with applied ceramic coatings including: PA/TiN, PA/AlTiN and PA/ TiN/SiN. The images of the template (substrate, Fig. 2) clearly show areas where glass fibres are present.

Significant differences in the surface topography are observed for substrates containing ceramic coatings, which was confirmed by visual inspection. Figure 3 shows an example of the surface of a PA/TiN ceramic coating on a polyamide substrate and its linear image.

The surface of the ceramic coatings shows corrugations, cracks and significant unevenness. Over the course of the cracks and on the extension of the cracks are locally observed areas that appear separated by a threshold area or surrounded by a crack. The tests of thickness of the ceramic coatings (Table 5) show, that they feature much higher values of the thickness, compared to the metallic coatings. The technological process of producing such coatings was designed for obtaining higher values of the coating thickness, compared to the metallic coatings which should prove adequate transparency to visible light.

The spectrum of the characteristic X-ray radiation obtained using the EDS detection system for a selected microarea of the samples provided information on which particles are present in the tested sample. Comparing the intensity of the lines that correspond to the individual particles, semi-quantitative elemental content information was obtained. The EDS analysis of the surface of the coatings performed in the area shown in the image demonstrated the presence of these particles, which were vaporized on the polyamide substrate. There were also phosphorus, calcium, and zinc present in smaller quantities. The presence of these particles is most likely
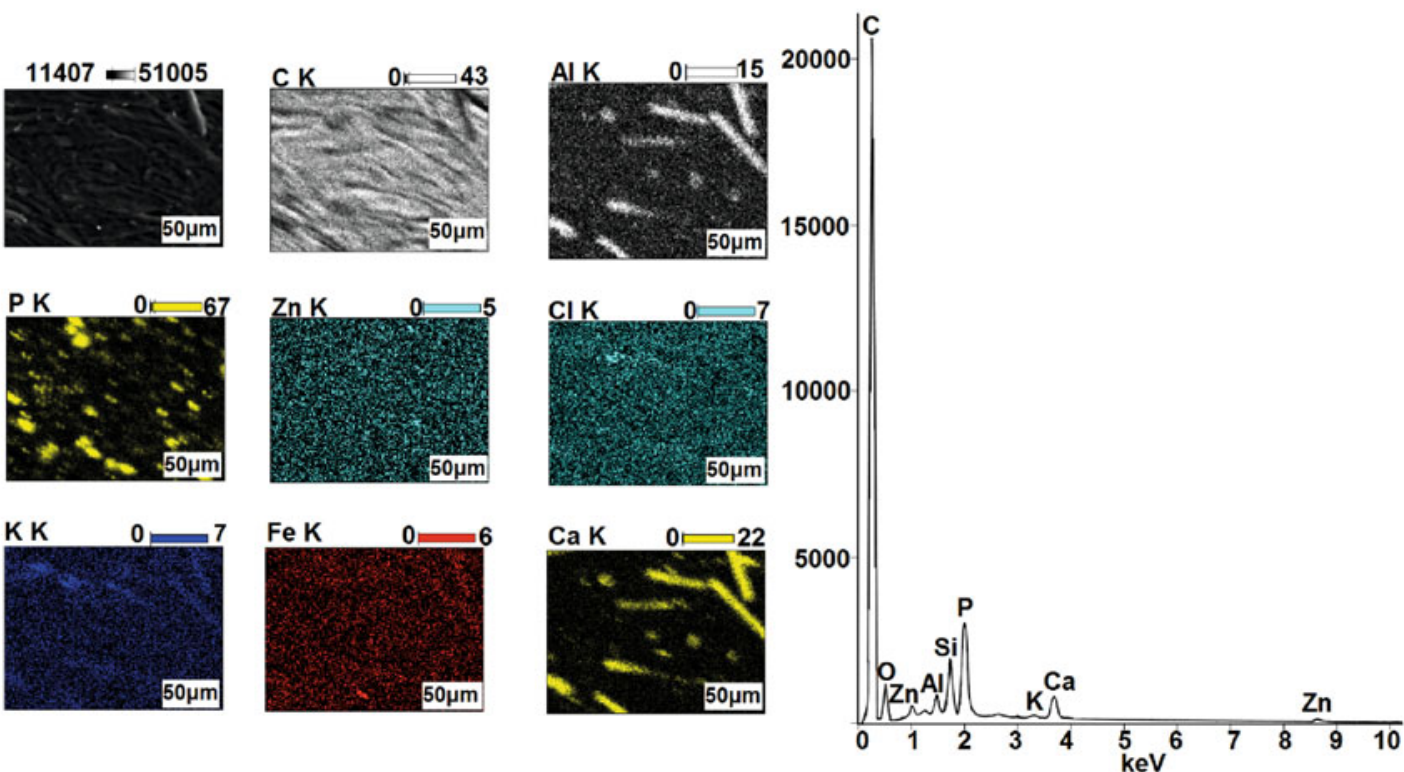

Figure 2. Results of the SEM-EDS tests (surface and linear distribution) on the polyamide (Ultramid®A3XZG5) substrate
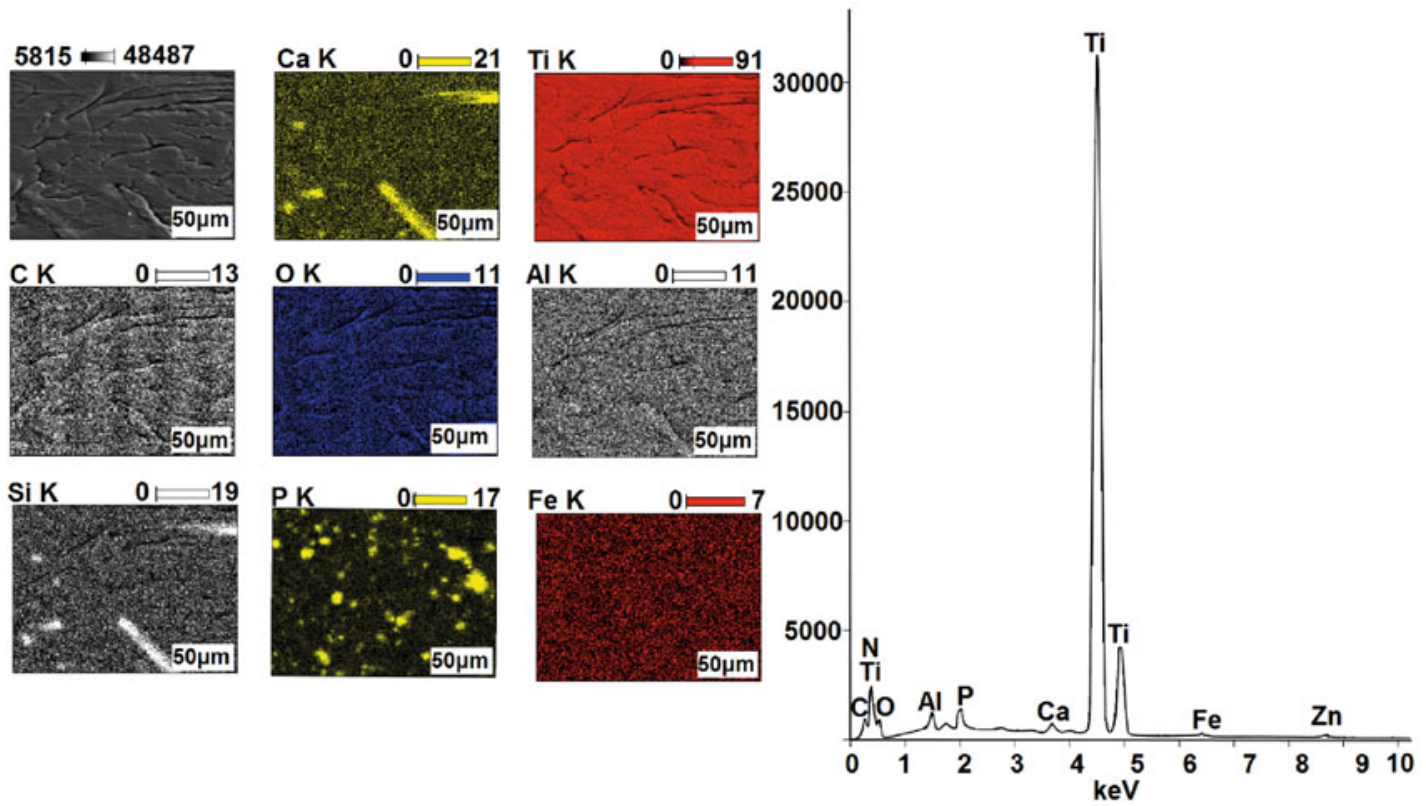

Figure 3. Results of the SEM-EDS tests (surface and linear distribution) on a PA/TiN coating 
associated with leftover catalyzers, incombustibles or other substances used in the production of the plastic.

\section{Results of ICP-AES analysis}

ICP-AES analysis included samples of polyamide Ultramid $^{\circledR}$ A3XZG5 and polycarbonate LEXAN ${ }^{\circledR} 141 \mathrm{R}$ substrates and the applied metallic: $\mathrm{PC} / \mathrm{Ti}, \mathrm{PC} / \mathrm{Ni}$ and $\mathrm{PC} / \mathrm{Cr}$ and ceramic coatings: PC/TiN, PC/AlTiN and $\mathrm{PC} / \mathrm{TiN} / \mathrm{SiN}$. The purpose of ICP-AES analysis was to provide a quantitative determination of the particles in the metallic and ceramic coatings applied to the selected substrates (Table 6).

The particles were determined in the sample of the template (substrate) of polyamide - Ultramid ${ }^{\circledR}$ A3XZG5 ultimately used to produce the ceramic coatings were $\mathrm{Ti}, \mathrm{Al}$, and Si. However, for the polycarbonate template LEXAN ${ }^{\circledR} 141 \mathrm{R}$, the following particles were determined: $\mathrm{Ti}, \mathrm{Ni}$, and $\mathrm{Cr}$. The Ti and $\mathrm{Al}$ contents in the polyamide substrate were 15.95 and $528.8 \mathrm{ppm}$, respectively. There is a significant quantity of these particles in the plastic that do not form a part of the polyamide chain, and they are most likely leftover catalyzers, non-combustibles or contaminants infiltrating the plastic during the production process. For the polycarbonate (LEXAN $\left.{ }^{\circledR} 141 \mathrm{R}\right)$ template, the quantities of $\mathrm{Ti}, \mathrm{Ni}$, and $\mathrm{Si}$ particles are small and range from $0.14 \mathrm{ppm}$ for $\mathrm{Ni}$ to $5.30 \mathrm{ppm}$ for $\mathrm{Ti}$. The Ti content in the sample with the PA/TiN ceramic coating was $1869 \mathrm{ppm}$. The $\mathrm{N}$ content was not determined because the ICP-AES analysis was conducted in a vacuum and the determined $\mathrm{N}$ content would be false. For the AlTiN ceramic coating, the determined quantities of titanium and aluminium differed substantially and amounted to $927.00 \mathrm{ppm}$ for $\mathrm{Ti}$ and $1237.00 \mathrm{ppm}$ for Al. The higher $\mathrm{Al}$ content in the PA/AlTiN coating may be caused by the method of vaporization of the coating or the higher relation of this particle to the polyamide substrate. By comparing the results of the ICP-AES tests to the SEM-EDS tests, a correlation between the obtained test results can be observed.

For example, the peaks on the linear distribution from the SEM-EDS from the PA/AITiN sample exhibit a higher content of $\mathrm{Al}$ compared to $\mathrm{Ti}$, which is confirmed from the ICP-AES method results. The ICP-AES tests performed on the TiN/SiN coating confirmed the results of the SEM-EDS analysis and the linear distribution shows that the peak corresponding to Ti has the highest value. The particle contents in the samples with applied metallic coatings of $\mathrm{Ti}, \mathrm{Ni}$ and $\mathrm{Cr}$ are similar and amount to: $29.58 \mathrm{ppm}, 30.25 \mathrm{ppm}$ and $28.83 \mathrm{ppm}$, respectively. Similarly to the ceramic coatings, the metallic coating tests also demonstrated correlations between the ICP-AES and SEM-EDS analysis results.

\section{CONCLUSIONS}

In this work, we have performed feasibility tests using magnetron sputtering technology to produce coatings on selected structural elements of firefighter helmets to protect against infrared radiation in accordance with PN-EN 171.

The following parameters were used to characterise the transmittance-reflection properties of the developed coatings:

- light transmittance coefficient (light transmittance);

- average spectral infrared transmittance coefficient over a wavelength range from 780 to $1400 \mathrm{~nm}$;

- average spectral infrared transmittance coefficient over a wavelength range from 780 to $2000 \mathrm{~nm}$;

- average spectral infrared reflection coefficient over a wavelength range from 780 to $2000 \mathrm{~nm}$.

For metallic coatings envisioned in the use of viewfinders in firefighter helmets, the value of the light transmittance coefficients and infrared transmittance coefficients over a range of 780-2000 $\mathrm{nm}$ were at levels corresponding to the marking of the filters: 4-3, $4.4,4-2.5,4-2,4-1.7,4-1.4$, and 4-1.2 according to the PN-EN171:2005 standard. The results obtained in this study demonstrate that for cases regarding these coatings, the maximum value of the average spectral infrared transmittance coefficient occurred over the range from 780-1400 nm. For the transparent samples, a positive result was recorded for the $\mathrm{PC} / \mathrm{Cr}$ and $\mathrm{PC} / \mathrm{Ni}$ coatings when tested to determine if they would fulfil the criterion of increased reflection of infrared radiation. The ceramic coatings on the non-transparent material, which possessed an infrared reflection coefficient in the range of 780 to $2000 \mathrm{~nm}$ were characterized by low levels of infrared radiation blockage (below 60\%). For this reason, these coatings were disqualified for use in the personal protection equipment used for protection against infrared radiation. The appropriate direction of further studies for both transparent and non-transparent construction elements for firefighter helmets should concern testing of metallic coatings. Testing on metallic coatings applied on the viewfinders of helmets should aim for developing a coating using magnetron sputtering. The coating properties should allow the elimination of the necessary wavelengths so that the transmittance coefficients in the infrared would conform to the requirements of the standard PN-EN 171:2005 for two wavelength ranges

Table 6. Results from the determination of particles in the metallic and ceramic coatings

\begin{tabular}{|c|c|c|c|c|c|c|}
\hline \multirow{2}{*}{ No. } & \multirow{2}{*}{ Sample } & \multicolumn{5}{|c|}{ Contents [ppm] } \\
\hline & & $\mathrm{Ti}$ & $\mathrm{Al}$ & $\mathrm{Si}$ & $\mathrm{Ni}$ & $\mathrm{Cr}$ \\
\hline 1 & $\begin{array}{l}\text { LEXAN }^{\otimes} 141 \mathrm{R} \\
\text { (template) }\end{array}$ & 5.30 & - & - & 0.14 & 0.32 \\
\hline 2 & $\mathrm{PC} / \mathrm{Ti}$ & 29.58 & - & - & - & - \\
\hline 3 & $\mathrm{PC} / \mathrm{Ni}$ & - & - & - & 30.25 & - \\
\hline 4 & $\mathrm{PC} / \mathrm{Cr}$ & - & - & - & - & 28.83 \\
\hline 5 & $\begin{array}{c}\text { Ultramid }^{(\pi} \mathrm{A} 3 \mathrm{XZG5} \\
\text { (template) }\end{array}$ & 15.95 & 528.80 & ND & - & - \\
\hline 6 & $\mathrm{PA} / \mathrm{TiN}$ & 1869.00 & - & - & - & - \\
\hline 7 & PA/AITiN & 927.00 & 1237.00 & - & - & - \\
\hline 8 & $\mathrm{PA} / \mathrm{TiN} / \mathrm{SiN}$ & 2005.00 & - & 861.00 & - & - \\
\hline
\end{tabular}

ND - not detected; detection threshold for Si $3.012 \mathrm{ppm}$. 
(780-1400 nm and 780-2000 nm). For metallic coatings used to modify non-transparent materials, further research should likely examine nickel based coatings, as these are characterized by high nano-hardnesses and high levels infrared radiation shielding. In addition, SEM tests of the metallic coatings demonstrated an even distribution of the surface particles and appropriate degrees of filling of the spaces between the particles, confirming the conditions used for the deposition of metallic coatings.

Based on the test results, we can conclude that the magnetron sputtering method should be further developed for metallic coatings based on their structure, transmittance-reflection properties and resistance parameters. This methodology could provide an alternative to classical vacuum deposition methods used to produce protective layers in personal protection equipment.

\section{ACKNOWLEDGEMENTS}

This research was funded by the National Centre for Research and Development, Research Grant No. ROB001401/ID 14/1.

\section{LITERATURE CITED}

1. Standards Association of Poland. (2006). Polish standard: Personal eye protection equipment. Face covers and viewfinders used in firemen helmets of high effectiveness in the area of industrial safety, used by the firemen, medical emergency teamsand rescue services. PN-EN 14458:2006.

2. Standards Association of Poland. (2005). Polish standard: Personal eye protection. Filters protecting against infrared radiation. PN-EN 171:2005.

3. Dietzel, Y., Przyborowski, W., Nocke, G., Offermann, P., Hollstein, F. \& Meinhardt, J. (2000). Investigation of PVD arc coatings on polyamide fabrics. Surf. Coat. Technol. 135, 75-81. DOI: 10.1016/S0257-8972(00)00917-8.

4. Wasa, K. \& Hayakawa, S. (1992). Handbook of sputter deposition technology. Noyes, USA: Park Ridge.

5. Dobrzański, L.A. \& Dobrzańska-Danikiewicz, A.D. (2011). Obróbka powierzchni materiałów inżynierskich (89-136). Open Access Library. International OCSCO World Press. http://www. openaccesslibrary.com/index.php?id $=81$

6. Kawate, M., Hashimoto, A.K. \& Suzuki, T. (2003). Oxidation resistance of $\mathrm{Cr} 1-\mathrm{x} \mathrm{Al}$ x N and Ti $1-\mathrm{x} \mathrm{Al} \mathrm{x} \mathrm{N} \mathrm{films.} \mathrm{Surf.}$ Coat. Technol. 165, 163-167. DOI: http://dx.doi.org/10.1016/ S0257-8972(02)00473-5

7. Ghrib, T., Tlili, B., Nouveau, C., Benlatreche, Y., Lambertin, M., Yacoubi, N. \& Ennasri, M. (2009). Experimental investigation of the mechanical micro structural and thermal properties of thin CrAIN layers deposited by PVD technique for various aluminum percentages. Phys. Proce. 2, 1327-1336. DOI: 10.1016/j.phpro.2009.11.099.

8. Bingyao Deng, Xiong Yan, Qufu Wei. \& Weidong Gao. (2007). AFM characterization of nonwoven material functionalized by ZnO sputter coating. Mater. Character. 58, 854-858. DOI: 10.1016/j.matchar.2006.08.002.

9. Qufu Wei, Qiuxiang Xu, Yibing Cai, Weidong Gao. \& Congzhi Bo. (2009). Characterization of polymer nanofibers coated by reactive sputtering of zinc. J. Mater. Proces. Technol. 209, 2028-2032. DOI: 10.1016/j.jmatprotec.2008.04.068.

10. Barshilia, H.C., Jain, A. \& Rajam, K.S. (2003). Structure, hardness and thermal stability of nanolayered TiN/CrN multilayer coatings. Vacuum 72, 241-248. DOI: 10.1016/j. vacuum.2003.08.003.

11. Barshilia, H.C., Prakash, M.S., Jain, A. \& Rajam, K.S. (2005). Structure, hardness and thermal stability of TiAlN and nanolayered TiAlN/CrN multilayer films. Vacuum 77, 169. DOI: 10.1016/j.vacuum.2004.08.020.

12. Grips, V.K., Selvi, V.E., Barshilia, H.C. \& Rajam, K.S. (2006). Effect of electroless nickel interlayer on the electrochemical behavior of single layer $\mathrm{CrN}$, TiN, TiAlN coatings and nanolayered TiAlN/CrN multilayer coatings prepared by reactive dc magnetron sputtering. Electrochem. Acta 51, 3461. DOI: 10.1016/j.electacta.2005.09.042.

13. Barshilia, H.C. \& Rajam, K.S. (2004). Structure and properties of reactive DC magnetron sputtered $\mathrm{TiN} / \mathrm{NbN}$ hard superlattices. Surf. Coat. Technol. 183, 174-183. DOI: 10.1016/j. surfcoat.2003.09.070.

14. Barshilia, H.C., Prakash, M.S., Poojari, A. \& Rajam, K.S. (2004). Corrosion behavior of nanolayered $\mathrm{TiN} / \mathrm{NbN}$ multilayer coatings prepared by reactive direct current magnetron sputtering process. Thin Solid Films 460, 133-142. DOI: 10.1016/j. tsf.2004.01.096.

15. Barshilia, H.C., Rajam, K.S. \& Sridhara Rao, D.V. (2006). Characterization of low temperature deposited nanolayered $\mathrm{TiN} / \mathrm{NbN}$ multilayer coatings by cross-sectional transmission electron microscopy. Surf. Coat. Technol. 200, 4586-4593. DOI: 10.1016/j.surfcoat.2005.04.016.

16. Barshilia, H.C., Rajam, K.S., Jain, A., Gopinadhan, K. \& Chaudhary, S. (2006). A comparative study on the structure and properties of nanolayered $\mathrm{TiN} / \mathrm{NbN}$ and TiAlN/TiN multilayer coatings prepared by reactive direct current magnetron sputtering. Thin Solid Films 503, 158-166. DOI: 10.1016/j. tsf.2005.12.074.

17. Tlili, B., Nouveau, C., Walock, M.J., Nasri, M. \& Ghrib, T. (2012). Effect of layer thickness on thermal properties of multilayer thin films produced by PVD. Vacuum 86, 1048-1056. DOI: 10.1016/j.vacuum.2011.09.008.

18. Lewis, D.B., Wadsworth, I., Münz, W.D., Kuzel Jr., R. \& Valvoda, V. (1999). Structure and stress of TiAlN/CrN superlattice coatings as a function of $\mathrm{CrN}$ layer thickness. Surf. Coat. Technol. 116-119, 284-291. DOI: 10.1016/S02578972(99)00132-2.

19. Panjan, M., Šturm, S., Panjan, P. \& Čekada, M. (2007). TEM investigation of TiAlN/CrN multilayer coatings prepared by magnetron sputtering. Surf. Coat. Technol. 202, 815-819. DOI: 10.1016/j.surfcoat.2007.05.084.

20. Dubas, S.T., Limsavarn, L., Iamsamai, C. \& Potiyaraj, P. (2006). Assembly of polyelectrolyte multilayers on nylon fibers. J. Appl. Polym. Sci. 101, 3286-3290. DOI: 10.1002/app.23826. 21. Cho, K.H., Park, J.E., Osaka, T. \& Park, S.G. (2005). The study of antimicrobial activity and preservative effects of nanosilver ingredient. Electrochim. Acta 51, 956-960. DOI: 10.1016/j.electacta.2005.04.071.

22. Qufu Wei, Xueliang Xiao, Dayin Hou, Heng Ye \& Fenglin Huang. (2008). Characterization of nonwoven material functionalized by sputter coating of copper. Surf. Coat. Technol. 202, 2535-2539. DOI: 10.1016/j.surfcoat.2007.09.022.

23. Chiba, K. \& Futagami, A. (2008). Enhanced bending stability of carbon-nanotube-reinforced indium tin oxide films on flexible plastic substrates. Appl. Phys. Lett. 93, 013114. DOI: http://dx.doi.org/10.1063/1.2951596

24. Sim, E., Kim, H., Park, J. \& Lee, M. (2009). Highly enhanced mechanical stability of indium tin oxide film with a thin Al buffer layer deposited on plastic substrate. Surf. \& Coat. Technol. 204, 309-312. DOI: 10.1016/j.surfcoat.2009.07.028.

25. Lewis, J., Grego, S., Chalamala, B., Vick, E. \& Temple, D. (2004). Highly flexible transparent electrodes for organic lightemitting diode-based displays. Appl. Phys. Lett. 85, 3450-3452. DOI: http://dx.doi.org/10.1063/1.1806559.

26. Moezzi, A., McDonagh, A.M. \& Cortie, M.B. (2012). Zinc oxide particles: Synthesis, properties and applications. Chem. Engine. J. 185-186, 1-22. DOI: 10.1016/j.cej.2012.01.076. 27. Misiano, C., Simonetti, E., Cerolini, P. \& Staffetti, F. (1991). Proc. 33 th society of vacuum coaters annual conference, SVC, pp. 105. 
28. Tong, T.W., Swathi, P.S. \& Cunnington Jr. G. (1989). Reduction of Radiative Heat Transfer in Thermal Insulations by Use of Dielectric Coated Fibers. Int. Comm. Heat Mass Transf. 16, 851-856.

29. Hass, D.D., Prasad, B.D., Glass, D.E. \& Wiedemanm, K.E. (1997). NASA Contractor Report NASA-97-cr201733, NASA Langly.

30. Wolański, R. (2008). PhD dissertation. Technology and materials for preparation of thermal protection against infrared and microwave radiation. University of Science and Technology. Materials and Ceramics Engineering Department, Krakow, Poland.

31. Leja, E., Precht, W. \& Wolański, R. (2007). Mthods of deposition of coatings on personal protection equipment of rescue services: Development trends in the rescue technologies and technical equipment. Conference materials. September 2007 (pp. 62-70). Junior Firemen Academy of State Fire Department in Krakow, Poland.

32. Gralewicz, G., Owczarek, G. \& Kubrak, J. (2012). Interference filters protect against harmful infrared radiation on hot workplaces. Occup. Heal. Saf. 5, 12-15.

33. Kim, S.K., Kim, T.H., Whole, J. \& Rie, K.T. (2000). TiCN coatings on aluminum alloy formed by MO-PACVD. Surf. Coat. Technol. 131, 121-126. DOI: 10.1016/S0257-8972(00)00831-8. 34. Rainforth, W.M., Leonard, A.J., Perrin, C., BedollaJacuinde, A., Wang, Y., Jones, H. \& Luo, Q. (2002). High resolution observations of friction-induced oxide and its interaction with the worn surface. Tribol. Int. 35, 731-748. DOI: http://dx.doi.org/10.1016/S0301-679X(02)00040-3 